06

\title{
Хлорид-гидридная газофазная эпитаксия полуполярного слоя AIN(1012) на наноструктурированной подложке Si(100)
}

\author{
(C) В.Н. Бессолов, М.Е. Компан, Е.В. Коненкова , В.Н. Пантелеев \\ Физико-технический институт им. А.Ф. Иофффе РАН, Санкт-Петербург, Россия \\ E-mail: lena.triat@mail.ioffe.ru
}

Поступило в Редакцию 7 октября 2019г.

В окончательной редакции 7 октября 2019г.

Принято к публикации 10 октября 2019г.

\begin{abstract}
Предложен метод синтеза гексагонального слоя $\mathrm{AlN}$ на подложке $\mathrm{Si}(100)$ с наноструктурированной $V$-образной поверхностью, для которой угол между наклонной плоскостью „нанохребта“ и $\mathrm{Si}(100)$ составляет $47^{\circ}$. Показано, что метод хлорид-гидридной газофазной эпитаксии на такой подложке позволяет сформировать полуполярный слой $\mathrm{AlN}(10 \overline{1} 2)$ при минимальной полуширине рентгенодифракционной кривой качания $\omega_{\theta} \sim 60$ arcmin. Обнаружено, что спектры комбинационного рассеяния света полуполярного слоя $\operatorname{AlN}(10 \overline{1} 2)$ содержат дополнительные пики на кривых комбинационного рассеяния света, связанные с фононами $A_{1}(\mathrm{TO})$ и $E_{1}(\mathrm{TO})$, в отличие от полярного слоя $\mathrm{AlN}(0001)$, где дополнительно проявляется пик $A_{1}(\mathrm{LO})$.
\end{abstract}

Ключевые слова: полуполярный нитрид алюминия, хлорид-гидридная эпитаксия, комбинационное рассеяние света.

DOI: 10.21883/PJTF.2020.02.48944.18061

Нитрид алюминия (AlN) является привлекательным материалом для создания датчиков на основе поверхностных акустических волн, светодиодов для ультрафиолетовой области спектра [1], а также в качестве буферного слоя для синтеза нитрида галлия. Приборы электроники на основе III-нитридных полупроводников создаются в основном на базе гексагональных кристаллов, синтезированных в направлении оси $c$. Однако использование плоскости (0001) в III-нитридных оптоэлектронных приборах приводит к появлению эффекта Штарка из-за сильной пьезоэлектрической поляризации. Для того чтобы избежать негативного влияния этого явления, в последние годы создаются слои и оптоэлектронные приборы на основе неполярных и полуполярных структур III-нитридов на подложках сапфира [2], $3 C-\mathrm{SiC} / \mathrm{Si}(100)$ [3] и $\mathrm{Si}(100)$ [4].

Расчет зависимости полной поляризации от угла наклона плоскости роста гексагонального кристалла относительно плоскости в направлении $c$ показывает, что пьезоэлектрическая поляризация становится нулевой для неполярной ориентации и для полуполярной ориентации с углом наклона около $45^{\circ}$ для $\mathrm{InGaN} / \mathrm{GaN}$ [5]. Углы между полуполярными плоскостями и осью $c$ гексагонального AlN различаются и составляют 31.64, 58.01 и $61.59^{\circ}$ для $(10 \overline{1} 3),(11 \overline{2} 2)$ и $(10 \overline{1} 1)$ соответственно [5]. Угол между плоскостями $\operatorname{AlN}(10 \overline{1} 2)$ и $\operatorname{AlN}(0001)$ составляет $43^{\circ}$.

Цель настоящей работы - выяснить условия формирования и свойства полуполярного слоя $\mathrm{AlN}$, синтезированного методом хлорид-гидридной газофазной эпитаксии (HVPE) на $V$-образной наноструктурированной подложке кремния $\mathrm{Si}(100)$. Для выполнения поставленной цели на подложке $\mathrm{Si}(100)$ с точностью ориентации поверхности $\pm 0.5^{\circ}$ по технологии Wostec [6] формировалась $V$-образная наноструктура, которая имела „нанохребты“ с величиной периода между ними $70 \mathrm{~nm}$ и высотой „хребта“ 30-50 nm (рис. 1). Видно, что подложка $\mathrm{Si}(100)$ может характеризоваться как $V$-наноструктурированная подложка с углом между плоскостью „нанохребта“ и плоскостью $\mathrm{Si}(100)$ величиной $\varphi \sim 47^{\circ}$ (рис. 1). Как известно, угол в $\mathrm{AlN}$ между плоскостями $\mathrm{Si}(111)$ и $\mathrm{Si}(100)$ имеет величину около $54^{\circ}$. Тогда можно предположить, что синтез проводился на $V$-структурированной подложке с гранями $\mathrm{Si}(111)$ с разориентацией около $7^{\circ}$ (рис. 2).

Для сравнения свойств полуполярного и полярного слоев нитрида алюминия дополнительно синтезировался слой $\mathrm{AlN}(0001)$ на плоской подложке в аналогичном температурно-временно́м процессе. Эпитаксиальный рост слоев осуществлялся методом HVPЕ при соотношении потоков в зоне роста $\mathrm{H}_{2}: \mathrm{NH}_{3}=2: 1$ при температуре $1080^{\circ} \mathrm{C}$. Толщина слоев AlN была около $2 \mu \mathrm{m}$. Структурные характеристики слоев AlN определялись методами рентгенодифракционного анализа, сканирующей электронной микроскопии (СЭМ), комбинационного рассеяния света (КРС). При рентгеноструктурных измерениях кривые качания регистрировались аналогично [7]. Комбинационное рассеяние света исследовалось с помощью рамановского спектрометра MRS 320. Исследования проводились при комнатной температуре аналогично [8].

Экспериментальные результаты для слоев $\mathrm{AlN}(0001)$ были следующими.

Рентгенодифракционный анализ показал, что полярный слой $\mathrm{AlN}(0001)$, синтезированный на плоской подложке $\operatorname{Si}(111)$, имеет полуширину кривой качания рентгеновской дифракции $\omega_{\theta} \sim 45 \operatorname{arcmin}$, а полуполярный слой $\mathrm{AlN}$, синтезированный на $V$-наноструктури- 


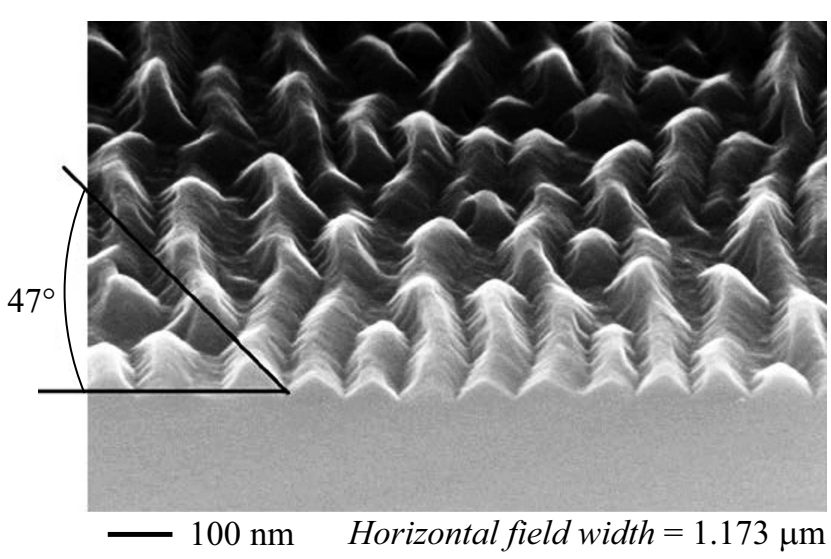

Рис. 1. СЭМ-изображения поверхности подложки $\mathrm{Si}(100)$.

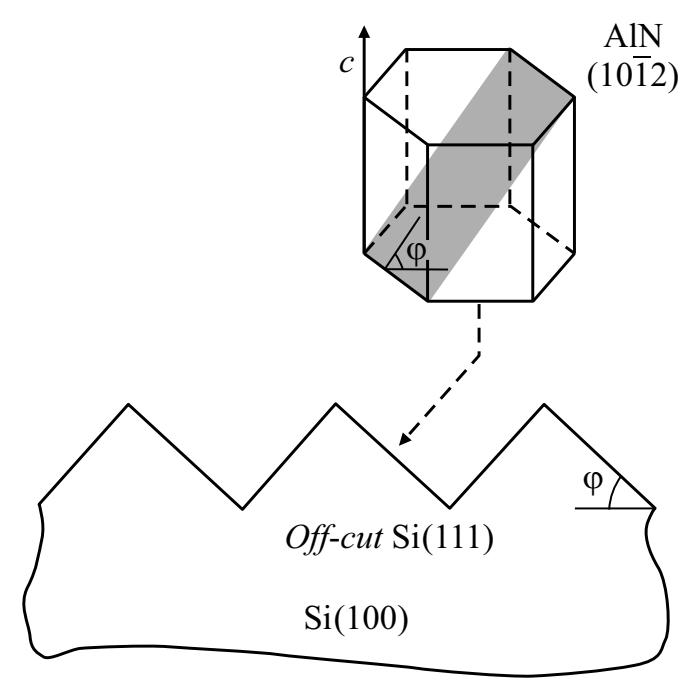

Рис. 2. Схема формирования слоя $\mathrm{AlN}(10 \overline{1} 2)$ на $V$-наноструктурированной подложке $\mathrm{Si}(100)$ с наклонными плоскостями „нанохребтов“ $\mathrm{Si}(111)$ с разориентацией в $7^{\circ}$.

рованной подложке, имеет поверхность роста (1012) с $\omega_{\theta} \sim 60$ arcmin.

Изображения, полученные при помощи сканирующего электронного микроскопа, выявили, что поверхность $\operatorname{AlN}(10 \overline{1} 2)$ на наноструктурированной подложке $\mathrm{Si}(100)$ имеет существенно бо́льшую шероховатость, чем поверхность $\operatorname{AlN}(0001)$ на подложке $\operatorname{Si}(111)$, но $\operatorname{AlN}(0001)$ содержит на поверхности трещины.

Спектры КРС слоев $\mathrm{AlN}(0001)$ и $\mathrm{AlN}(10 \overline{1} 2)$ существенно различались (рис. 3). Спектры КРС структур $\mathrm{AlN}$ содержали линии, принадлежащие кремниевой подложке: пики $E_{2}($ high $)-655.6 \mathrm{~cm}^{-1}$ с одинаковыми $\left(\sim 7 \mathrm{~cm}^{-1}\right)$ величинами полной ширины на половине высоты (FWHM) пиков. Спектры КРС полярных и полуполярных слоев $\mathrm{AlN}$ имеют существенные различия: полярный слой содержал пик при $887.5 \mathrm{~cm}^{-1}$, который связывают с фононом $A_{1}(\mathrm{LO})$ [9], а полуполярный пики 668.1 и $907.3 \mathrm{~cm}^{-1}$, обусловленные фононами $E_{1}(\mathrm{TO})$ и $E_{1}(\mathrm{LO})[9]$. Пики $A_{1}(\mathrm{TO})$ различались как по положению максимумов $\left(607\right.$ и $617 \mathrm{~cm}^{-1}$ для полярных и полуполярных слоев соответственно), так и по интенсивности (у полуполярного интенсивность выше) (рис. 3).

Уширение спектров КРС обычно является результатом рассеяния фононов, вызванного мелкими зернами блочного слоя, градиентом напряжений в гетероструктуpe. Для объемных кристаллов AIN FWHM пика $E_{2}($ high имеет величину $3-5 \mathrm{~cm}^{-1}$, а для поликристаллического слоя она может составлять $50 \mathrm{~cm}^{-1}$ [9].

Ранее нами было показано, что применение наноструктурированной $V$-образной поверхности $\mathrm{Si}(100)$ с гранями $\mathrm{Si}(111)$ приводит в методе газофазной эпитаксии из металлоорганических соединений к росту полуполярного слоя $\mathrm{GaN}(10 \overline{1} 1)$ [10]. В настоящей работе использовался нанорельеф подложки $\mathrm{Si}(100)$, в котором наклонные грани соответствовали $\mathrm{Si}(111)$ с разориентацией около $7^{\circ}$ (рис. 1). При формировании слоя направление с гексагонального кристалла AlN перпендикулярно плоскости $\mathrm{AlN}(0001)$, которая, по нашему мнению, будет формироваться на разориентированной на $7^{\circ}$ плоскости $\mathrm{Si}(111)$ „нанохребта“ с углом к плоскости $\mathrm{Si}(100)$ около $47^{\circ}$. Поскольку полуполярная плоскость (1012) имеет угол с плоскостью $\operatorname{AlN}(0001)$ также $47^{\circ}$, синтез в такой геометрии может сформировать именно плоскость (1012) параллельно плоскости подложки $\mathrm{Si}(100)$ (рис. 2). Можно предположить, что вариация параметров наноструктурированной подложки открывает еще одну возможность инженерии полуполярных слоев. Примерно одинаковое значение FWHM пиков $E_{2}(h i g h)$ для полярных и полуполярных структур подтверждает данные рентгеноструктурного анализа, свидетельствующие о примерно одинаковом качестве полуполярных и полярных слоев $\mathrm{AlN}$.

Усиление пика $A_{1}(\mathrm{TO})$ и появление пика $E_{1}(\mathrm{TO})$ в случае полуполярной структуры (по сравнению с полярной) можно интерпретировать следующим образом. Спектры КРС зависят как от кристаллической

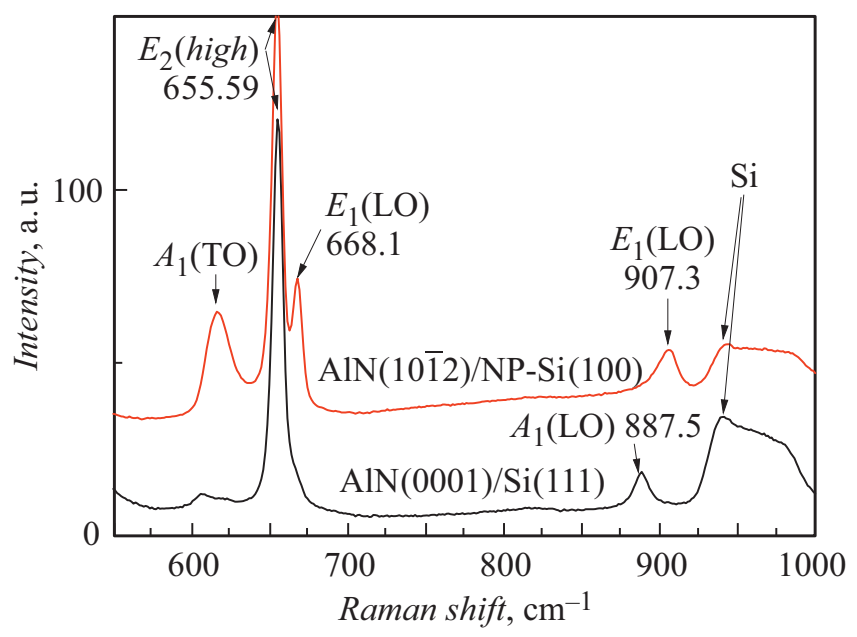

Рис. 3. Спектры КРС структур $\operatorname{AlN}(10 \overline{1} 2) / \operatorname{Si}(100)$ и $\operatorname{AlN}(0001) / \operatorname{Si}(111)$. 
ориентации, так и от концентрации носителей заряда в слое. Комбинационно-активные режимы рассеяния света определяются направлением падения лазерного луча и направлением поляризации кристалла, т.е. правилом отбора комбинационного рассеяния. Как известно, в неполярных кристаллах $\mathrm{GaN}$ активны режимы рассеяния света с пиками $E_{2}\left(\right.$ high) и $A_{1}(\mathrm{TO}), E_{1}(\mathrm{TO})$, а для полярных кристаллов $\mathrm{GaN}$ проявляются пики $E_{2}(h i g h)$ и $A_{1}(\mathrm{LO})$ [11]. Наши результаты не противоречат этому правилу. В спектрах КРС полуполярного $\mathrm{AlN}(10 \overline{1} 2)$ проявляются пики $E_{2}($ high $)$ и $A_{1}(\mathrm{TO}), E_{1}(\mathrm{TO})$, а в случае полярного $\mathrm{AlN}(0001)-E_{2}($ high $), A_{1}(\mathrm{LO})$. Поскольку концентрация носителей в слоях была одинаковой, спектры КРС могут быть использованы в качестве экспрессметодики для определения наличия полуполярных слоев.

Таким образом, в результате гетероэпитаксии AlN на подложке $\mathrm{Si}(100)$ с $V$-образной наноструктурированной поверхностью с плоскостью „нанохребта“ $\mathrm{Si}(111)$, разориентированной на $7^{\circ}$, при использовании метода хлорид-гидридной газофазной эпитаксии формируется полуполярный слой $\operatorname{AlN}(10 \overline{1} 2)$ с $\omega_{\theta} \sim 60$ arcmin. Показано, что спектры комбинационного рассеяния света полуполярного слоя содержат дополнительные пики, связанные с фононами $\mathrm{A}_{1}(\mathrm{TO})$ и $\mathrm{E}_{1}(\mathrm{TO})$, в отличие от полярного слоя $\mathrm{AlN}(0001)$.

\section{Благодарности}

Авторы благодарят компанию ООО „Квантовый кремний“ (Москва) за предоставление подложек $\mathrm{Si}(100)$, наноструктурированных по технологии Wostec, а также В.К. Смирнова за полезные дискуссии и М.П. Щеглова за рентгенодифракционные измерения.

\section{Конфликт интересов}

Авторы заявляют, что у них нет конфликта интересов.

\section{Список литературы}

[1] Matsumoto T., Khan M.A., Maeda N., Fujikawa S., Kamata N., Hirayama H. // J. Phys. D: Appl. Phys. 2018. V. 52. P. 115102.

[2] Liu T., Zhang J., Su X., Huang J., Wang J., Xu K. // Sci. Rep. 2016. V. 6. P. 26040.

[3] Dinh D.V., Presa S., Akhter M., Maaskant P.P., Corbett B., Parbrook P.J. // Semicond. Sci. Technol. 2015. V. 30. P. 125007.

[4] Bessolov V., Kalmykov A., Konenkova E., Kukushkin S., Myasoedov A., Poletaev N., Rodin S. // J. Cryst. Growth. 2017. V. 457. P. 202-206.

[5] Romanov A.E., Baker T.J., Nakamura S., Speck J.S. // J. Appl. Phys. 2006. V. 100. P. 023522.

[6] Smirnov V.K., Kibalov D.S., Orlov O.M., Graboshnikov V.V. // Nanotechnology. 2003. V. 14, P. 709-715.

[7] Bessolov V.N., Zubkova A.B., Konenkova E.V., Konenkov S.D., Kukushkin S.A., Orlova T.A., Rodin S.N., Rubets V.P.,
Kibalov D.S., Smirnov V.K. // Phys. Status Solidi B. 2019. V. 256. P. 1800268.

[8] Бессолов В.Н., Компан М.Е., Коненкова Е.В., Пантелеев В.Н., Родин С.Н., Щеглов М.П. // Письма в ЖТФ. 2019. T. 45. B. 11. C. 3-5.

[9] Kuball M., Hayes J.M., Prins A.D., Van Uden N.W.A., Dunstan D.J., Shi Y., Edgar J.H. // Appl. Phys. Lett. 2001. V. 78. P. 724-726.

[10] Бессолов В.Н., Коненкова Е.В., Орлова Т.А., Родин С.Н., Щеглов М.П., Кибалов Д.С., Смирнов В.К. // Письма в ЖТФ. 2018. Т. 44. В. 12. C. 45-51.

[11] Ma B., Jinno D., Miyake H., Hiramatsu K., Harima H. // Appl. Phys. Lett. 2012. V. 100. P. 011909. 